\title{
Epilepsy: Attitude and Awareness among Students of Professional Social Work
}

\author{
Prakashi Rajaram* $^{*}$ and Priya Treesa Thomas ${ }^{\dagger}$
}

\section{Abstract}

\begin{abstract}
Epilepsy is one of the most common neurological disorders that affect approximately 50 million people worldwide, with the prevalence of $1 \%$ in the population. Nearly $80 \%$ of people with epilepsy are found in developing countries, where the disease remains a major public health problem. It is not only because of its health implications but also for its social, cultural, psychological and economic effects. The person with epilepsy goes through many difficulties such as unpredictability of the seizures, adjustmental demands on personal and work life, family coping, problems in marital relationship, issues surrounding children, economic burden, and stigma about the disease apart from the access to treatment. Managing a chronic illness such as epilepsy involves more than managing medical problems. Social workers, as change agents, can fulfil their roles as educators, counsellors, and patient-advocates by helping patients and families to gain insight into the implications of chronic illness. The present cross sectional study was conducted among the Master of Social Work (MSW) students specialising in Medical and Psychiatric Social Work, with an attempt to look at the Knowledge and
\end{abstract}

Additional Professor of Psychiatric Social Work, Department of Psychiatric Social Work, National Institute of Mental Health and Neuro Sciences NIMHANS),Bangalore-560029; drprakashi.manipur@gmail.com

† Psychiatric Social Worker, Department of Psychiatric Social Work (NIMHANS); priyathomasat@gmail.com 


\begin{abstract}
Attitude about Epilepsy. Thirty one students of Master of Social Work course with Medical and Psychiatric Social Work $($ males $=9$; females $=22$; age $=23.61$, range 22-28 years) from different colleges in South India filled the questionnaire developed to assess the knowledge and attitudes about Epilepsy. All the respondents had heard about Epilepsy. The study revealed that while there is good awareness about Epilepsy among the students, majority of them felt that persons with Epilepsy should have restrictions in movement $(84 \%)$ and that they have limitations in employment (58\%). The implications of the study from knowledge development, research and practice are discussed.
\end{abstract}

Keywords: Epilepsy, Social, Cultural, Psychological and economic effects, Medical social work, Psychiatric social work.

\title{
Introduction
}

Epilepsy is a common chronic neurological condition that is characterized by recurrent unprovoked epileptic seizures (Blume et al, 2001). The disease affects approximately 50 million people worldwide and more than 10 million persons with epilepsy (PWE) in India. Its prevalence is about $1 \%$ of our population (Sridharan \& Murthy, 1999), higher in the rural (1.9\%) compared to the urban population (0.6\%) (Leonardi \& Ustun, 2002; Pahl \& de Boer, 2005). The burden of epilepsy as estimated using the disability-adjusted life years (DALYs) accounts for $1 \%$ of the total burden of disease in the world, excluding PWE in our country face. This in turn leads to escalation of the disease burden (Jain \& Chandra, 2008). It is estimated that the highest age-specific prevalence rate of 6.5 per 1,000 occurred in the 10- to 19-year-old age group (Radhakrishnan et al, 2000).

Epilepsy is usually controlled, but not always cured with medication. However, surgery may be considered in difficult cases. Epilepsy constitutes a major public health problem not only for its seizure activity, but also due to the social and cultural stigma attached to it. Epilepsy is one of the oldest diseases to be described 
in literature, Ayurveda system of medicine describes 'Apasmara' about twenty centuries ago and Hippocrates identified the disease 3500 years ago. In the past, epilepsy was associated with religious experiences and demonic possession. Stigma continues to this day, in both the public and the private spheres. The person with epilepsy goes through many difficulties such as - unpredictability of the seizures, adjustmental demands on personal and work life, family coping, problems in marital relationship, issues surrounding children, economic burden, and stigma about the disease apart from the access to treatment.

Management of Epilepsy moves beyond the sphere of medical treatment mainly due to the social effects attached with the disease (Jacoby, 2002). Psychosocial issues associated with the disease have received significant attention in literature (Collings, 1990; Dodrill et al, 1984; Lau et al 2001). Studies show that affective disorders were more commonly associated with epilepsy (Mensah et al 2006; 2007). Deepened emotionality, depression (Robertson, Trimble \& Townsend, 1987; Plioplys, 2003) and fear were the most common psychiatric co-morbidities reported. There are also organic personality changes associated with long standing Epilepsy. The changes brought about by repeated seizures in the brain tend to affect memory, cognitive and behavioural functioning of the person.

The stigma faced by people suffering from epilepsy is well documented (Jacoby \& Austin, 2007; Scambler \& Hopkins, 1990). High score on stigma correlates with negative feelings, worry and anxiety. Acceptance of persons with Epilepsy in the society is very low, and it could start from the school or the family itself. The stigma attached to Epilepsy affects not only the affected individual, but his/her family as well, in terms of influencing the life choices made by the patient, parents, spouse and siblings. Stigma in workplace can lead to underemployment, unemployment or discrimination in workplace. Uncontrolled seizures often lead to absenteeism and inconsistency in the work (Jacoby, Gorry \& Baker, 2005; DeBoer, 2005).

A disturbance in productive occupational functioning makes the patients dependent on others for financial security. This, along with 
the myths and misconceptions associated with anti epileptic medication affects the treatment compliance of PWE (Buck et al 1997). Similar to the severe mental illness, there is a downward drift observed in the person's and family's standard of living secondary to the onset of seizures. Since financial security forms a cultural basis for many goals in life such as quality education, choice of profession, good alliance and so on, this becomes crucial in the family life of the affected individual.

The impact of Epilepsy on individual and family varies across their life span. This being one of the most common neurological problems in children, it has serious effect on their education and behaviour (Osborne, Shafer \& Dean, 2003; Vinayan, 2006). Compared to men, women with epilepsy are reported to have worse psychosocial outcome (Gopinath, Sarma \& Thomas, 2011; Dansky, Anderman \& Anderman, 1980). Marriage is a major issue for young women with Epilepsy (Wada et al, 2004) so as childbearing. Psychosocial pathology would be expected to be the greatest in women of childbearing age, when one considers the stress of marriage, changed circumstances, and childbearing together (Aggarwal et al. 2006; Santosh et al 2007; Saburi, Mapanga \& Mapanga, 2006). Heredity, seizure recurrence during pregnancy, and the effect of drugs on the foetus are the associated concerns for the woman and her spouse (Crawford et al, 1999).

It is evident that managing a chronic illness such as epilepsy involves more than managing medical problems. It also entails managing psychological and social considerations, identity adjustments, role changes and altered body image or life style. All require physical, social, and emotional adaptations for both the patient and the family.

Rajaram \& Thomas, (2009) have reported about that the clinical social workers need to fulfil their roles as educators, counsellors, and patient-advocates by helping patients and families to gain insight into the implications of chronic illness. Due to the highly individualistic nature of problems faced by persons with epilepsy, the interventionists have to make therapeutic programmes customized to the various needs of individual patients and their families. 
The National Association of Social Workers (NASW, 2004) describes the role of social workers as "All social workers, regardless of practice settings, will inevitably work with clients facing acute or long-term situations involving life-limiting illness, dying, death, grief, and bereavement. Using their expertise in working with populations from varying cultures, ages, socioeconomic status, and non-traditional families, social workers help families across the life span in coping with trauma, suicide, and death, and they must be prepared to assess such needs and intervene appropriately." In order to take up challenges as described by the NASW, the social work professionals should have positive attitude and scientific temper toward this need.

\section{Awareness among Students of Professional Social Work}

An in-depth understanding of what epilepsy is and how it can have an effect on the person and their caregivers will help the mental health professionals to target their interventions accordingly. Social Work Professionals have a greater role as part of multidisciplinary team to provide psychosocial care and ensure treatment adherence. In a disease that is potentially treatable, ensuring adequate care and follow up become an important goal of intervention.

\section{Methods and Materials}

In order to promote the quality of life of people with Epilepsy and to promote inclusion in social activities, social work professionals can contribute to a great extent. With this background, the present study was conducted among the Master of Social Work (MSW) students specialising in Medical and Psychiatric Social Work, with an attempt to assess the Knowledge and Attitude about Epilepsy. The data was collected purposively from students posted for inservice exposure to a Tertiary Referral centre for Neurology, Neurosurgery and Psychiatry. Thirty one students of Master of Social Work course from different colleges in South India filled the questionnaire developed to assess the Knowledge and attitudes about Epilepsy. The questionnaire used in this study is a modified version of the one used in the 'Knowledge, Attitude and Practice (KAP) study on Epilepsy' by Radhakrishnan et al (2000) previously 
carried out in Kerala, South India. The original questionnaire had 24 items with the domains Knowledge, Attitude and Practice about Epilepsy. This has been adapted for use with different population such as school teachers (Thacker et al, 2008; Pandian et al, 2006), Pre university students (Goel et al, 2011) as well as patients (Gourie Devi et al, 2010) and caregivers with Epilepsy. All the questions were simple with yes or no responses, and are used to assess knowledge, understanding and attitude based on individual items, rather than being given a domain score. The modified questionnaire with 19 items on Knowledge, Understanding and Attitude to Epilepsy was face validated and content validated through a jury of experts in Epilepsy and Psychiatric Social Work. The study questionnaires were distributed manually and they were printed in English. The data collection was done in the month of May 2013. All data were analyzed using $R$ Software and a frequency test was used for item wise analysis and $t$ test was conducted to find out the gender difference among the Social Work students on the knowledge, understanding and attitude.

\section{Results}

Of the thirty one students who completed the questionnaire, nine were males and 22 were females. Mean age of the respondents was 23.61 (range 22-28 years). All the respondents had heard about Epilepsy. Seventy-seven percent of the respondents reported to be familiar with a person with Epilepsy. Forty-two percent respondents had witnessed an epileptic attack at least once in their lifetime. At the same time, only $23 \%$ responded that they thought they were well informed about Epilepsy (Table 1).

$84 \%$ of the respondents showed no clear knowledge about the incidence of Epilepsy. Majority of the participants responded that its occurrence is one in 1000 population. In terms of etiological factors, $71 \%$ answered that seizures could occur due to a variety of causes. Many of the respondents (61\%) felt that Epilepsy medication had to be continued lifelong." 
Table 1. Understanding of Epilepsy

\begin{tabular}{|l|l|l|l|l|}
\hline $\begin{array}{l}\text { SI } \\
\text { No }\end{array}$ & \multicolumn{1}{|c|}{ Questions } & $\begin{array}{c}\text { Yes } \\
(\boldsymbol{\%})\end{array}$ & $\begin{array}{c}\text { No } \\
(\boldsymbol{\%})\end{array}$ & $\begin{array}{c}\text { Don't } \\
\text { Know (\%) }\end{array}$ \\
\hline 1 & Epilepsy is a mental disease. & 39 & 54 & 7 \\
\hline 2 & Epilepsy is a neurological disease. & 100 & 0 & 0 \\
\hline 3 & Epilepsy is a hereditary disease. & 23 & 65 & 13 \\
\hline 4 & Epilepsy is a contagious disease. & 10 & 45 & 45 \\
\hline 5 & Epilepsy is caused by ancestor's sin. & 0 & 61 & 39 \\
\hline 6 & Epilepsy can be cured by treatment. & 39 & 61 & 0 \\
\hline 7 & $\begin{array}{l}\text { There is no problem even if one or two } \\
\text { doses of medicine are missed. }\end{array}$ & 19 & 62 & 19 \\
\hline
\end{tabular}

The students reported a good understanding about Epilepsy as a Neurological Disease (Table 1). Yet, 10\% considered Epilepsy to be contagious, and $45 \%$ were not sure about the transmittable nature of the disease. Majority of the students (61\%) did not feel that epilepsy could be cured by treatment. $62 \%$ of the participants also felt that there could be no problem even if one or two doses of medicine were missed in AED treatment.

Table 2. Attitudes towards Epilepsy

\begin{tabular}{|c|c|c|c|c|}
\hline $\begin{array}{l}\text { Sl } \\
\text { No }\end{array}$ & Questions & $\begin{array}{l}\text { Yes } \\
(\%)\end{array}$ & $\begin{array}{l}\text { No } \\
(\%)\end{array}$ & $\begin{array}{l}\text { Don't } \\
\text { Know }\end{array}$ \\
\hline 1 & $\begin{array}{l}\text { I will object to my children playing with a child } \\
\text { with Epilepsy. }\end{array}$ & 29 & 61 & 10 \\
\hline 2 & $\begin{array}{l}\text { I will object to a close relative of mine (child/ } \\
\text { brother/sister) marrying a person with Epilepsy. }\end{array}$ & 42 & 39 & 19 \\
\hline 3 & $\begin{array}{l}\text { Persons with Epilepsy should be employed in } \\
\text { the same jobs as others are. }\end{array}$ & 58 & 39 & 3 \\
\hline 4 & Epilepsy is a hindrance to happy life. & 20 & 32 & 48 \\
\hline 5 & $\begin{array}{l}\text { Society discriminates against persons with } \\
\text { epilepsy. }\end{array}$ & 29 & 52 & 19 \\
\hline 6 & $\begin{array}{l}\text { Epilepsy patients cannot work like other people } \\
\text { (cannot be employed). }\end{array}$ & 23 & 74 & 3 \\
\hline 7 & $\begin{array}{l}\text { My family will be concerned, if I work with } \\
\text { children with Epilepsy. }\end{array}$ & 61 & 7 & 32 \\
\hline 8 & $\begin{array}{l}\text { Persons with Epilepsy should not be allowed to } \\
\text { go out alone. }\end{array}$ & 84 & 16 & 0 \\
\hline
\end{tabular}


respondents, while $48 \%$ were not sure. This attitude was more in male students than in female students $(t=2.57 ; p=0.02)$. A significant group of students $(84 \%)$ also felt that the person with Epilepsy should not be allowed to go out alone. Families' concern with Epilepsy was considered to be significantly negative by about $61 \%$ of the respondents, while $32 \%$ were not sure about the family's response. A negative attitude was also evident among the students in terms of employability of the patients with epilepsy (58\%). There was no significant difference among the students on knowledge, understanding or attitude about Epilepsy based on various demographic variables.

\section{Discussion}

There are many studies which use different methods to evaluate knowledge, attitude and practice towards epilepsy, both in developed and developing countries among various populations such as patients, family members, teachers, and students as well as the general public. The information is usually collected by face-toface interviews and specific questionnaires. The current study revealed that all the respondents had heard of epilepsy, which is similar to the trends reported in other studies conducted among school, college and university students and the public in different parts of India (Pandian et al, 2006; Agarwal, 2008; Gouri-Devi, 2010). Many of the respondents were also familiar with someone with Epilepsy. The present study was done among the social work students, as compared to that of Rambe \& Sjahrir, 2002 (Primary School Teachers), Pandian et al 2006 (12 th grade students), and Radhakrishnan et al 2000 (Public).

This study brings out the negative attitude of social work students towards Epilepsy in certain domains such as restriction of their movements and employability. 58\% report that people with Epilepsy cannot work like others, but $29 \%$ say that they will object to their children playing with a child with Epilepsy, and $42 \%$ convey that they would object to a close relative marrying a person with Epilepsy. 
Misunderstanding, negative attitude and prejudice about Epilepsy contribute to stigma and discrimination, leading to increased anxiety, depression and poor coping among the population with Epilepsy. In recent years, there has been an increasing emphasis on the educational needs of patients with chronic disorders in order to help the patients and families to gain better control of their life and optimize the quality of life. Epilepsy is a disorder with a high degree of stigma and prejudice, and the success of its treatment depends very much on the patients' treatment compliance and the understanding of the disorder. Social Work professionals who work as part of the multidisciplinary team in medical setting are in ideal position to fill the gaps in patients' knowledge and contribute towards optimizing their quality of life.

In order to work effectively with the PWE and facilitate change in coping and quality of life, social workers need to have an understanding about Epilepsy and its implications. As the above findings depict, the need for awareness programmes on Epilepsy among Social Work students is high. Such programmes would help in preparing the students' skill base for clinical practice. Based on these, there is a case for inclusion of the topic in MSW curriculum and exposure through field work training. The results encourage the educators of social work to train the social work students adequately on sensitivity and empathy towards the person in context.

The findings of the study have to be taken in the light of certain limitations. The sample was purposively selected and size was small. There is a need for further large scale studies in order to substantiate the findings. Since the questionnaire in the present study has item wise analysis done, a cumulative score for knowledge, attitude and understanding could not be arrived at. Such a finding would have thrown more light in terms of predictors for knowledge and attitude.

\section{References}

Agarwal, P., Mehndiratta, M. M., Antony, A. R., Kumar, N., Dwivedi, R. N., Sharma, P., and Kumar S. (2006). Epilepsy in India: Nuptiality behavior and fertility. Seizure 15:409-415. 
Agarwal, A. K. (2008). Social classification: The need to update in the present scenario. Indian Journal of Community Medicine 33:50-1.

Blume, W. T., Luders, H.O., Mizrahi, E., Tassinari, C., Emde Boas, W. \& Jerome Engel Jr. (2001). Glossary of ictal semiology. Epilepsia, Vol.42, No. 9, pp. 1212-1218

Buck, D., Jacoby, A., Baker G. A. and Chadwick, D. (1997). Factors influencing compliance with antiepileptic drug regimes. Seizure. 6:8793.

Collings, J. (1990). Psychological well-being and Epilepsy. Epilepsia 31:418 $-442$

Crawford, P., Appleton, R., Betts, T. et al. (1999). Best practice guidelines for the management of women with epilepsy. Seizure 8: 201-217. Available on line at http:/ / www. idealibrary.com

Dansky, L. V., Andermann, E., and Andermann F. (1980). Marriage and fertility in epileptic patients. Epilepsia 21:261-271

DeBoer, H. M. Overview and perspective of employment in people with epilepsy. Epilepsia 2005; 1(46)2- 4.

Dodrill, C. B., Breyer, D.N., Diamond, M.B., Dubinsky, B. L. and Geary, B. B. (1984) Psychosocial Problems among adults with Epilepsy. Epilepsia 25: 168 - 175

Dodrill, C. B., Beier, R., Kasparick, M., Tacke, I., Tacke, U and Tan, S. Y. (1984). Psychosocial problems in adults with epilepsy: Comparison of findings from four countries. Epilepsia 25: 176-83.

Goel, D., Dhanai, J.S., Agarwal, A.K., Mehlotra, V. And Saxena, V.(2011). Knowledge, attitude and practice of epilepsy in Uttarakhand, India. Annals of Indian Academy of Neurology 14:116-9.

Gopinath, M., Sarma, P. S, and Thomas, S. V. (2011). Gender-specific psychosocial outcome for women with epilepsy. Epilepsy and Behaviour 20(1):44-7.

Gourie Devi, M., Singh, V. and Bala, K. (2010). Knowledge, Attitude and Practice among patients of epilepsy attending tertiary hospital in Delhi, India and review of Indian studies. Neurology Asia 15:225-32.

Hermann, B. P and Whitman, S. (1984). Behavioral and personality correlates of epilepsy: a review, methodological critique, and conceptual model. Psychol Bull. 95:451-97.

Hills ,M. D. (2007). The psychological and social impact of epilepsy. Neurology Asia. 12(S1):10-12.

Jacoby, A, Austin, J. (2007). Social stigma for adults and children with epilepsy. Epilepsia. 9(48)69. 
Jacoby, A. (2002). Stigma, epilepsy, and quality of life. Epilepsy \& Behavior. 3(6, Supplement 2):10-20

Jacoby, A., Gorry, J. and Baker, G. A. (2005). Employers' attitudes to employment of people with epilepsy: still the same old story? Epilepsia. 46(12):1978-87.

Jain, S. and Chandra, P. S. (2008). Epilepsy: A comprehensive textbook. In: Engel, J. Jr,. Pedley, T. A, (Eds) Lippincott Williams \& Wilkins. (2). New York: Cambridge University Press. 2885 - 2889

Johnson, E. K. Jones, J. E., Seidenberg, M., and Hermann, B. P. (2004). The relative impact of anxiety, depression, and clinical seizure features on health-related quality of life in epilepsy. Epilepsia; 45(5):544-50

Lau, V. W, Y., Lee, T. M. C, Ng, P. K. K and Wang, V. C. N. (2001) Psychosocial adjustment of people with epilepsy in Hong Kong. Epilepsia 42: 1169 - 1175

Leonardi, M. and Ustun, T. B (2002). The global burden of epilepsy. Epilepsia. 43 (Suppl. 6):21-5.

Mensah, S. A., Beavis, J. M., Thapar, A. K. and Kerr, M. P.(2007). A community study of the presence of anxiety disorder in people with epilepsy. Epilepsy and Behavior 11(1):118-24.

Mensah, SA., Beavis, JM., Thapa,r AK., and Kerr, MP. (2006). The presence and clinical implications of depression in a community population of adults with epilepsy. Epilepsy \& Behavior.8 (1):213-9.

National Association of Social Workers. (2004).NASW Standards for Social Work Practice in Palliative and End of Life Care. Washington, DC

Osborne, Shafer, P., and Dean, P. (2003). Clinical challenges for learning, behavior and mood in children with epilepsy. Epilepsy Behavior. 4: 98100.

Pahl, K. and De, Boer, H. M. (2005). Atlas: epilepsy care in the world. Geneva: WHO, Epilepsy and Rights; 72-3.

Pandian, J. D., Santosh, D., Kumar, T. S., Sarma, P. S. and Radhakrishnan, K. (2006). High school students' knowledge, attitude, and practice with respect to epilepsy in Kerala, southern India. Epilepsy $\mathcal{E}$ Behaviour 9:492-7.

Perrine, K. R and Cognett, S. (1994) Neurobehavioral problems in Epilepsy. Epilepsia 12: 129 - 152

Plioplys , S. (2003). Depression in children and adolescents with epilepsy. Epilepsy \& Behavior. 4 (Supplement 3):39-45.

Radhakrishnan, K., Pandian, J. D., Santoshkumar, T., Thomas, S. V., Deetha, T. D., Sarma, P. S., et al. (2000). Prevalence, knowledge, 
attitude and practice of epilepsy in Kerala, South India. Epilepsia 41:1027-35

Rajaram, P and Thomas, P. T. (2009). Adult persons with Epilepsy Psychiatric Social Work Perspective. Roshni Journal of professional Social Work. 5: 50 - 70.

Rambe, A. S. and Sjahrir, H. (2002). Awareness, attitudes and understanding towards Epilepsy among school teachers in Medan, Indonesia. Neurological Journal of Southeast Asia 7, 77 - 80

Robertson, M. M., Trimble, M. R. and D. R. A. Townsend. (1987). Phenomenology of depression in epilepsy. Epilepsia 28, 364-372

Saburi, G. L., Mapanga, K. G. and Mapanga, M. B. (2006). Perceived family reactions and quality of life of adults with epilepsy. Journal of Neuroscience Nursing 38: 156 - 165

Santosh, D, Kumar, T. S., Sarma, P. S., Radhakrishnan, K. (2007). Women with onset of epilepsy prior to marriage: Disclose or conceal? Epilepsia 48:1007-10.

Scambler, G. and Hopkins, A. (1990). Generating a model of epileptic stigma: the role of qualitative analysis. Social Science and Medicine 30:1187-1194

Sridharan, R. and Murthy, B. N.(1999). Prevalence and pattern of epilepsy in India. Epilepsia. 40:631-6

Thacker, A. K. Verma, A.M. and Ji, R. et al. (2008). Knowledge awareness and attitude about epilepsy among schoolteachers in India. Seizure.17:684-690.

Theodor, M. Margarete. P. (2005). Psycho educational program for patients with epilepsy. Disease management and health outcomes; 4(13):185-199.

Vinayan, K. P. (2006). Epilepsy, antiepileptic drugs and educational problems. Indian Pediatrics, 43, 786-794. Retrieved from http:/ / www.indianpediatrics.net/sep2006/sep-786- 794.htm

Wada, K. Iwasa. H, Okada. M, Kawata. Y, Murakami. T, Kamata. A. et al (2004). Marital status of patients with epilepsy with special reference to the influence of epileptic seizures on the patient's married life. Epilepsia 8(45):33-36. 